\title{
CRÓNICA DE LOS ESTUDIOS SOBRE EL SIGLO XVII (I)
}

Francisco Abad

$U N E D$

A Evangelina Rodriguez Cuadros

\section{PROPÓSITO}

Iniciamos con las presentes páginas una atención -que deseariamos ininterrumpida y regular- a la bibliografía que se vaya produciendo en torno al siglo XVII, tanto de textos o fuentes de la centuria que se publiquen como de estudios.

Por igual todo el siglo tiene interés, pues a la máxima floración literaria del primer tercio sucede la del segundo en pintura, y ya en las dos últimas décadas se inician entre nosotros los orígenes de la ciencia moderna; de ningún modo la historiografía admite hoy una decadencia sin más hacia finales de la época.

Nos proponemos por tanto dedicar nuestra atención analítico-crítica al Barroco español y a la introducción del pensamiento moderno en España; en el Seiscientos se producen buena parte de las aportaciones hispanas a la historia universal, y en concreto a su componente de historia de la cultura. El trabajo analítico estará dedicado a los estudios sobre la centuria; la interpretación propiamente dicha de algunos aspectos del período la hemos iniciado - $y$, sobre todo, deseamos desarrollarla- en otros escritos. De momento, nos ponemos pues a un primer artículo de crónica bibliográfica. 
El apogeo literario español de los primeros lustros del Seiscientos no hace falta subrayarlo, y puede quedar datado idealmente entre 1599 (fecha del Guzmán de Alfarache) y 1635 (año de la muerte de Lope de Vega). En su trabajo póstumo sobre la lengua del XVII, Menéndez Pidal ha venido a decirlo hablando de treinta años de esplendor de las letras barrocas: "El apogeo de la dilatada época barroca -escribe- ocurre en sus comienzos, a raíz de los primeros éxitos de las escuelas culterana y conceptista. Podemos considerarlo limitado a un período de treinta años, hasta la muerte de Lope de Vega, en el cual conviven los más grandes cultivadores del idioma... Es el cenit de la literatura espanoola. [...] Todo cuanto mejor tuvo que decir la lengua española lo dijo en estos treinta años. Ellos son la flor de la literatura hispana, y los siglos circundantes no parecen sino el ramaje de esa potente floración" '.

El maestro coruñés, aunque no lo diga, parece estar pensando en los años que van desde el Quijote hasta la muerte efectiva de Lope de Vega; en cualquier caso, queda el dato del apogeo de los más altos cultivadores del imaginario y de la lengua, en el tercio inicial del siglo barroco.

La edad áurea de la pintura española también es sabido que ocurre durante el Seiscientos. En su día, un especialista como Diego Angulo se expresó así: «La generación que nace (decía) aproximadamente con el siglo tiene una personalidad tan extraordinaria - Ribera, Zurbarán. Velázquez, Alonso Cano, Espinosa-, que aconseja agrupar y considerar a la mayor parte de los artistas que no son sus contemporáneos como estilísticamente anteriores o posteriores, correspondiendo por tanto cronológicamente al primero y último tercio del siglo. A quien guste $o$, siguiendo normas sobre todo de la historiografía del arte francesa, desee poner nombres de reyes a las diversas etapas estilísticas, podría sin gran violencia denominar los estilos de esos tres períodos estilos Felipe III (1598-1621), Felipe IV (1621-1665) y Carlos II (1665-1700) ?

Con posterioridad Alfonso Pérez Sánchez enuncia cómo el XVII constituye «con toda evidencia, el Siglo de Oro de la pintura española». dado que buena parte de nuestros nombres en la historia universal del arte son de ese momento. En concreto la generación de artistas que ha nacido entre 1590 y 1610 , y que llena el reinado de Felipe IV, da lugar a «la verdadera Edad de Oro de nuestra pintura», representando su mayor altura Ribera, Zurbarán, Velázquez y Alonso Cano ${ }^{3}$.

\footnotetext{
' Ramón Menéndez Pidal, "La lengua castellana en el siglo XVII», en el tomo XXVI/2 de su Historia de España, Madrid. Espasa-Calpe, 1986. pp. 3-137. 1971.

2 D. Angulo, «Pintura del siglo Xvilm. vol. XV de Ars Hispaniae, Madrid. Plus Ultra.
}

Alfonso Emilio Pérez Sánchez. «Pintura y Escultura», Historia.... XXV1/2. pp. 671-754. 
Tenemos, pues, y dicho en términos generales, un primer tercio de siglo de absoluto relieve literario, y otro segundo cuyas creaciones más logradas corresponden a los pintores; en cuanto a la filosofía, el pensamiento y la ciencia, es el siglo XVI el que está considerado como el de "la edad de oro» del pensamiento español ${ }^{4}$. Sabido resulta, no obstante, «el genio del siglo XVII», según decía Whitehead y ha repetido luego y reivindicado - por ejemplo- Noam Chomsky.

Lo que se da ya de introducción de la ciencia moderna en España durante el propio Seiscientos lo ha establecido López Piñero ${ }^{5}$. Señala este autor en términos generales cómo con la revolución científica del siglo XVII el saber natural «de ser un fenómeno marginal pasó a convertirse en un hecho central para la vida económica, política e intelectual». En cuanto a la ciencia española de la centuria, distingue en ella tres períodos: el tercio inicial del siglo, los cuarenta años centrales y las dos últimas décadas.

Sólo en los años centrales empezó a aceptarse algún componente moderno de la actividad científica, dice López Piñero, quien luego expone que nada más que «en las dos últimas décadas del siglo se produjo un movimiento de ruptura con el saber tradicional y sus supuestos». La conciencia del atraso científico español llevó a los renovadores a un programa de asimilación del saber moderno que sirvió de base para la posterior época ilustrada: el punto de partida del movimiento «fue la conciencia de que España había permanecido al margen del nacimiento de la ciencia moderna. Tal conciencia la expresaron públicamente por vez primera un grupo de científicos que en los últimos años del siglo rompieron abiertamente con los principios tradicionales, denunciaron el atraso científico español y proclamaron la necesidad de introducir en España de forma íntegra las nuevas corrientes». A estos intelectuales se les llamó despectivamente novatores.

Resulta en definitiva, y es lo que tiene establecido la historiografía desde hace unos veinte años, que el origen de la España dieciochesca viene de los lustros últimos de la centuria del Seiscientos. Refiriéndose así al padre Feijoo, otro especialista como Antonio Mestre ha podido escribir: «Los cuarenta años - dice- que preceden al Teatro crítico adquieren una complejidad inesperada, y su conocimiento contribuye a precisar los orígenes de la ciencia experimental, de la historia crítica o del influjo de las diversas corrientes del pensamiento europeo... Se trata, en el fondo, de la crisis de la cultura tradicional, de una forma de

+ Así lo hace José Luis Abellán en su Historia crítica del pensamiento español: vid. el volumen II (Madrid. Espasa-Calpe, 1979).

5 Cfr. como obra última de conjunto su libro Ciencia y técnica en la sociedad española de los siglo XVI y XVII, Barcelona. Labor, 1979. 
vida expresada por el Barroco" ${ }^{6}$. Entre Calderón y Feijoo - podemos decir para entendernos - no se ha dado, pues, la «indigencia mental» de la que todavía hablaba Domínguez Ortiz en los años cincuenta, y de la que se hacía eco el noble y gran Juan Reglá; se trata de un medio siglo de realidad bien distinta .

\section{Bibliografias COMENTADAS}

Hoy día asistimos a una gran explosión bibliográfica que hace que una sola persona sólo pueda haber leído de verdad parte bien limitada de esa literatura técnica existente; surge así la imperiosidad de recuentos que no sean una mera enumeración de títulos - muchas veces tomados de otras enumeraciones anteriores-, sino que indiquen también algo de su contenido respectivo y que, en definitiva, orienten. Las dificultades no obstante son muchas, empezando por el cierto esfuerzo de lectura personal que supone el componer un estado de la cuestión - por pequeño que sea-que no se limite a la mera enumeración de títulos; además, hay que contar con los disgustos que trae la imparcialidad, de los que se quejaba incluso Menéndez Pidal por haberle ellos quizá alcanzado, y antes que nada hay que tener la voluntad de esa imparcialidad: de nada sirven en el estudio la alabanza interesada o por inercia de los nombres consagrados o foráneos, y el simultáneo desconocimiento de la labor de los coetáneos o de quienes son más jóvenes, aunque desde luego humanamente se expliquen bien estas cosas. «Hay que recordar - decía en un párrafo lúcido Erich von Richthofen- que en investigación, aparte de seguir dócilmente lo que está en vogue, sólo encontramos escasos ejemplos de admiración de unos estudiosos hacia otros que sobresalen en ciertos terrenos o aspectos de la crítica literaria, y demasiado pocos investigadores consiguen distinguirse por aunar desacuerdo y respeto" ${ }^{8}$.

Sobre problemas históricos constituye en cierta medida un conjunto de «estados de cuestiones" el reciente volumen La historiografía en Oc-

- A. Mestre, Despotismo e ilustración en España, Barcelona, Ariel, 1976.

7 Cfr. J. Reglá y S. Alcolea. El siglo XVIII, Barcelona, Seix Barral, 1957.

* Limites de la crítica literaria y Analectas de filologia comparada. Barcelona. Planeta, 1976. Cfr. todas las pp. 11-59. y también por ejemplo - en otro orden de cosas- el artículo de Santos Juliá, «Una oleada de localismo» (de El Pais, 23 de octubre de 1986), donde se dice: «Se producen trabajos de una erudición a veces indigesta, o pequeñas incursiones que temen sobrepasar los límites de lo irrelevante... La obsesión localista se une así al proteccionismo oficial para desviar el trabajo de los historiadores hacia el peor de los particularismos... Se acabará por trazar como ideal de historiador un camino que va de la cuna a la tumba sin salir del término municipal: aquí nací, aquí estudié, de aquí investigo porque aquí me publican, aquí me muero.n 
cidente desde $1945^{9}$; aunque hay referencias de interés en distintos de sus capítulos (trata del concepto de «decadencia» en el Seiscientos Valentín Vázquez de Prada), aborda derechamente los tiempos modernos y el siglo XVII Pedro Molas en sus páginas sobre «La historia social de la España Moderna».

Molas llama la atención, por ejemplo, en torno a la necesidad de que los modernistas asciendan también en su interés hasta la baja Edad Media, y borren, por tanto, sus fronteras con los medievalistas propiamente dichos. Menciona algunos estudios sobre sociología cultural del XVII: teatro, poesía de cordel, cultura popular..., pidiendo no se teorice de un modo esquemático y por ello poco acorde con las complejidades reales; en cuanto a la «comedia» no remite no obstante a una obra mayor como la de Salomon ${ }^{10}$.

\section{ENSAYOS INTERPRETATIVOS DE CONJUNTO}

La historia de la acuñación de la expresión o troquel «Siglo de Oro», así como los contenidos que se le han dado y el devenir de las estimaciones acerca de la propia edad áurea, los ha trazado Juan Manuel Rozas en las tres primeras lecciones de su curso «El teatro en tiempos de Lope de Vega" ", y en el artículo "Siglo de Oro: historia de un concepto, la acuñación del término" ${ }^{12}$. Siguiendo el esquema de Rozas, aunque rectificando alguno de sus datos y apuntando alguna interpretación nueva, ha vuelto a referirse al tema Francisco Abad: «Materiales para la historia del concepto de "Siglo de Oro" en la literatura española» ${ }^{13}$, y "Otras notas sobre el concepto de "Siglo de Oro"»"

Las conclusiones alcanzadas por Rozas y F. Abad pueden esquematizarse en tres primeras:

a) Hace uso ya de la idea y la denominación de «Siglo de Oro» don Luis Josef Velázquez, a mediados del siglo XVIII.

b) La concepción la potencia el Romanticismo: Nicolás Böhl de Faber, Adolfo Federico Schack...

Y Pamplona, Eunsa, 1985.

11) Dieciséis textos monográficos referidos a la cultura del Barroco los comentamos brevemente en las Actas del Congreso internacional sobre Calderón y el teatro español del Siglo de Oro (Madrid, C.S.I.C., 1983); lamentamos ante nosotros mismos que el alejamiento que entonces teníamos respecto de nuestros libros no nos permitiese acudir al congreso calderoniano con unas páginas de mayor entidad.

Madrid, U.N.E.D., 1976.

12 Estudios sobre el Siglo de Oro, Madrid, Editora Nacional, 1984, pp. 411-428.

13 Analecta Malacitana, III/2, 1980, pp. 309-330.

14 Analecta..., VI/1, 1983, pp. 177-178. 
c) En el siglo XX será cuando se normalice el sintagma, muy empleado por Dámaso Alonso y - preferentemente en pluralpor don Ramón.

No obstante, a estas observaciones y a las restantes que puedan hacerse debe añadirse una de importancia: la historiografía que se interesa por las estructuras históricas, aquella que analiza el todo situacional concreto e interdependiente de una época, ha desechado como valedero el sintagma, y considera más racional y menos teñido ideológicamente hablar de "Renacimiento" y de "Barroco»; en este sentido don José Antonio Maravall se refiere a «el llamado, con una terminología un tanto trasnochada, Siglo de Oro en España" ${ }^{15}$.

Los filólogos, por su parte, hacen mucho uso ahora tanto de la expresión como de la equivalente "Edad de Oro". Incluso con cierta impropiedad, a las letras de los siglos XVIII, XIX y XX las denominan «literatura moderna y contemporánea».

Un ensayo de conjunto sobre los rasgos literarios y culturales del siglo XVII publicó en 1975 Emilio Orozco: nos referimos al capítulo suyo de la Historia de la literatura española que apareció entonces en la editorial Guadiana ${ }^{16}$; del mismo año es la interpretación de conjunto de Maravall La cultura del Barroco, y el tomo dedicado a la época de su serie de Estudios de historia del pensamiento español ${ }^{17}$.

Orozco y Maravall son dos de nuestros estudiosos mayores en temas del Seiscientos, el uno desde una sensibilidad fundamentalmente estética y literaria, el segundo con mayor interés por los hechos jurídico-políticos y sociales, y en definitiva de historia de las mentalidades; en los escritos de Orozco aún son visibles las huellas de concepciones historiográficas de décadas atrás, pero el conjunto de las publicaciones que ha hecho sobre los siglos XVI y XVII no sólo es de obligada consulta, sino que ofrece perspectivas y contenidos que no se encuentran en ningún otro estudioso.

En el capítulo al que aludimos el profesor granadino se refiere en un momento de modo global a la cultura barroca, y dice: «Si una nueva sociedad -y no sólo unos artistas y escritores- demanda y en cierto modo determina unas formas, géneros y estilos, nos explicamos que toda clase de inquietudes y sentimientos, sobre todo los que más conmueven a la época, sean los esenciales determinantes del estilo barroco. Por eso puede ofrecerse éste como el arte de la Contrarreforma, y también, por la misma razón, como el arte del Absolutismo.»

15 J. A. Maravall, La literatura picaresca desde la historia social, Madrid, Taurus. 1986.

in Historia..., II, Madrid, 1975, pp. 15-125.

17 José Antonio Maravall, La cultura.... Barcelona. Ariel, 1975; Estudios.... III. Madrid. Cultura Hispánica, 1975, 1984². 
Orozco dedica también sus páginas a una caracterización estilística del Manierismo y el Barroco, y sintetiza por ejemplo así: "Se trata, pues, de dos concepciones de fondo anticlásico por su complejidad y complicación, predominantemente intelectualista y estética en el Manierismo, y vital y sensorial en el Barroco, y cuyo sistema o principio estructural responde en el primer caso a la composición -esto es, dejando los elementos como desintegrados-, y en el segundo a la mezcla. en la que sus elementos se funden perdiendo su sentido independiente y pasando a ser un todo unido en su variedad" $1 \mathrm{~s}$.

La cultura del Barroco es libro bien conocido, y en este momento sólo vamos a destacar su organización general. El mismo orden y título de los capítulos dibuja ya el discurrir argumentativo: así «La cultura del Barroco como un concepto de época»; «La conflictividad de la sociedad barroca»; "Una cultura dirigida»; "Una cultura masiva»; "Una cultura urbana»; "Una cultura conservadora»; «Los recursos de acción psicológica sobre la sociedad barroca»; ...El Barroco nos aparece aquí definido en tanto un conjunto o estructura históricos, como una realidad político-social, cultural, etc., dada en un momento cronológico; no se trata, pues, sólo de un concepto de «estilo» aplicable intemporalmente.

Maravall se refiere en su ensayo a la crisis y a la conciencia de crisis durante el Seiscientos, y a las respuestas que para contener los tiempos idean y ponen en práctica las fuerzas conservadoras; surge así uno de los componentes que integran el pensamiento y las letras y artes de la centuria.

El volumen del propio Maravall de sus Estudios de historia... lleva el título específico de «El siglo del Barroco», y en el mismo se examinan los tipos de discurso seiscientistas de Quevedo, o de Saavedra Fajardo y de Gracián. Este hecho hay que tenerlo en cuenta, pues las interpretaciones del profesor valenciano acerca de la «comedia», de la picaresca y de Saavedra o Gracián son coherentes entre sí, y leídas aisladamente fuera del todo conjunto que forman, quedan desdibujadas y no se entienden en su exacta matización. Destacaremos sólo algunas cosas.

Maravall se adhiere efectivamente a la fecha de 1680 como la del final del Barroco y la de un cambio en la vida española: de 1670 a 1680 aproximadamente - dice- «un cambio de signo en la curva de la evolución demográfica, un restablecimiento inicial de la situación económica... y una penetración del pensamiento europeo, en su línea francesa cartesiana o gasendista y en su línea empirista inglesa, son factores que provocan un innegable cambio en el estado del país y preparan la mejoría — de todos modos no demasiado amplia ni intensa- del siglo

is Un escrito semejante al de Orozco aunque referido al XVI. es el de Juan Bautista Avalle-Arce. "Aproximaciones al Renacimiento literario español», ahora en Dintorno de una Época Dorada. Madrid. José Purrúa, 1978. pp. 1-56. 
de nuestra Ilustración». Por igual pide nuestro autor también se destierre la expresión «Siglo de Oro», imprecisa en su cronologia e «insoportablemente retórica».

En la conciencia de crisis del XVII, propone Maravall, vienen a parar dos realidades: la calamidad objetiva de los malos tiempos y «las penosas y criticables dificultades y que proceden de la inepta política de la monarquía». Para mitad del siglo nos hallamos ante unas gentes «que junto a desastres militares y pérdidas territoriales, junto a fracasos politicos y conjuras, junto a quiebras bancarias, cierres de comercio, manipulaciones de la moneda, aumento de tributos, sólo oyen hablar de atemorizar, de condenar, de castigar».

En definitiva, el profesor valenciano nos presenta la clave de la época en su situación de crisis social, y en las fuerzas de represión que se empeñan en mantener el ordenamiento establecido.

\section{LA «HISTORIA DE ESPAÑA» PIDALINA}

La Historia de España fundada en su día por Menéndez Pidal tiene ahora previsto dedicar cinco tomos (en seis volúmenes) a la centuria del Seiscientos; de esos volúmenes, tres están ya en la calle.

$\mathrm{El}$ programa editorial comprende un primer tomo dedicado a población, economía y sociedad, es decir, a «La crisis del siglo XVII», más otro último que se ocupará de "La transición del siglo XVII al XVIII"; otros dos volúmenes están dedicados a «La España de Felipe III» y «La España de Felipe IV", y por fin quedan los dos que tratan del pensamiento y la cultura toda: filosofía y teología, ciencia, letras y artes. Se encuentran hasta ahora en el mercado el ya aludido «El siglo del Quijote» en su volumen referente a la literatura y las artes, más los dos tomos respectivos que tratan de los dos Felipes 19.

La España de Felipe III consta de un estudio preliminar a cargo de Carlos Seco concebido - son sus palabras- a modo de aproximación panorámica, y del texto propiamente dicho debido a Ciriaco Pérez Bustamante. Con toda honradez hay que decir que los especialistas no se han sentido satisfechos con este tomo, ideologizado conservadoramente y poco atento, por tanto, a la real racionalidad de lo histórico. Además, por ejemplo, al Quijote no se le dedican sino nueve líneas equivocando una de sus fechas de publicación (quizá por errata), y teniéndolo en tanto reflejo esencial del alma española.

Pese a los reparos que puedan con honestidad hacérsele, se trata no

19 La España de Felipe III, Madrid. Espasa-Calpe. 1979; La España de Felipe IV. Madrid. Espasa-Calpe, 1982. 
obstante de un volumen con pasajes útiles y que a nosotros mismos nos ha servido con provecho antes, y que seguiremos utilizando "0.

En cuanto a la dedicación de Pérez Bustamante al monarca, sabido es cómo viene de atrás, y ya en 1950 cristalizó en su Felipe III. Semblanza de un monarca y perfiles de una privanza ${ }^{21}$; entonces, dibujaba esta fisonomía de la realidad política española bajo el rey: «La de un Imperio -escribió- en que un Monarca abúlico se inhibe casi totalmente de sus funciones de gobernante; un valido o primer ministro que busca en la quietud el fundamento de su poder, y una serie de virreyes, gobernadores y diplomáticos ambiciosos, enérgicos y activos, que obran por cuenta propia y sostienen el prestigio de la Monarquía frente a los enemigos exteriores y a la corrupción interior».

El tomo de la Historia pidalina dedicado a los años de Felipe IV es notoriamente de mayor relieve que el referente a su predecesor, y en el mismo colaboran investigadores bien serios. Simplemente destacaremos ahora que en el "Prólogo» de carácter global escrito por Francisco Tomás se encuentran páginas que hay que tener en cuenta cuando se considere el concepto moderno de España; en esas páginas se contiene también una fisonomía política de la época: "La monarquía absoluta como forma primera del Estado - escribe Tomás-. las naciones y su organización, las penurias crónicas y crecientes de la Hacienda Real, la política exterior montada sobre un rosario de guerras y las relaciones entre el rey cristianísimo y el romano pontífice, componen las diferentes piezas de un retablo que no es... sino el de la dramática peripecia de la España de Felipe IV".

En la Castilla del Barroco se gobernaba atemorizando, dice una vez nuestro autor: en ella Quevedo - podemos sugerir por nuestra cuenta - atemorizaba también quizá a quienes se encontraban movidos por el impetu ascensional, un Quevedo coherentemente exaltador del poder absoluto. Francisco Tomás habla de «el paradójico Quevedo, mordaz en ocasiones, adulador en otras, cuya Política de Dios y gobierno de Cristo es uno de los libros más retóricos y más aduladores del Barroco».

A John Elliott se debe en el volumen de La España de Felipe IV, una monografía fundamental: «El programa de Olivares y los movimientos de $1640{ }^{22}$; también de este hispanista de primera fila es por ejemplo la conferencia El Conde-Duque de Olivares y la herencia de Felipe $I^{23}$. Mencionamos la conferencia porque en ella aparecen

\footnotetext{
20 Vid. de momento "Quevedo y la tradición española», Caracterización de la litera. tura española y otros estudios, Madrid. Tapia, 1983, pp. 160-171.

21 Madrid, Real Academia de la Historia.

22 La España.... pp. 333-523.

23 Universidad de Valladolid, 1977.
} 
conceptos que un filólogo habrá de conocer si desea encontrar - creemos- el verdadero sentido de algunos textos literarios de la época; su tesis central es la que ya viene anunciada en el título, a saber: que el Conde-Duque intentaba conservar la herencia imperial de Felipe II ${ }^{24}$.

\section{AUTORES E INVESTIGACIONES}

De los autores de la escuela de filología española, es decir, de los discípulos y colaboradores de don Ramón en el Centro de Estudios Históricos, se ocuparon quizá más de temas del Seiscientos el propio don Ramón. Américo Castro. Montesinos. Moreno Báez, y sobre todo Dámaso Alonso. Luego han venido otros críticos atentos en especial a la centuria, como Orozco. Blecua. Alonso Zamora. Fernando Lázaro o el desaparecido Juan Manuel Rozas; desde luego existen estudiosos más jóvenes ya calificados, aunque en este primer artículo no vamos a entrar en sus obras, y están también los numerosos hispanistas franceses o de habla inglesa, bastantes de ellos de primera fila y que tantas cosas nos vienen enseñando 25 .

Entre los historiadores del siglo podemos mencionar a Dominguez Ortiz, Maravall, don Julio Caro, Reglá o Ricardo García Cárcel, más López Piñero por lo que se refiere a la historia de los saberes científicos, y Kamen, Elliott...

Dámaso Alonso sabido es que desde 1972 está publicando las Obras Completas, en las que ahora se halla recogida toda su obra gongorina, más los comentarios de textos, las páginas dispersas en torno a Cervantes y la novela realista moderna, etc. Pero como ha dicho algún autor -y nosotros mismo hemos repetido-, esta publicación viene siendo acogida con silencio; nadie parece haber subrayado que se trata, junto con la de Menéndez Pidal, de la más amplia tarea crítico-literaria llevada a cabo en nuestro siglo dentro del ámbito hispánico. Se diría que no siempre todos los autores tienen acceso a las revistas de relieve para hacer en ellas reseñas, y que quienes sí pueden más fácilmente es-

24 Cfr. provisionalmente el artículo ya aludido «Ouevedo y la tradición española».

25 A la dedicación editora o interpretativa de Zamora a Lope y Tirso. han de sumarse también sus páginas sobre la picaresca: recientemente $-y$ de conjunto- vid. la "Introducción" a los volúmenes anotados por él Novela picaresca española (Barcelona. Noguer. I. 1974). De J. M. Rozas cfr. la edición de Villamediana (Madrid. Clásicos Castalia), así como el Significado y doctrina del Arte Nuevo de Lope de Vega. Madrid, S.G.E.L.. 1976, y sus capítulos en la Historia de la Literatura, I, Madrid. U.N.E.D. (hay varias reimpresiones). 
cribir en las mismas no han pensado en hacerlo o no se han decidido a ello ${ }^{26}$.

\section{El TEATro del Barroco}

Dos planteamientos de conjunto existen - ambos bien conocidos-, en torno a la sociología de la «comedia» lopeveguesca: el de Noël Salomon, Lo villano en el teatro del Siglo de Oro (con este título está ahora en español), y el de Maravall, Teatro y literatura en la sociedad barro$\mathrm{ca}^{27}$. El segundo de ellos vamos a recogerlo ahora en abreviatura ${ }^{2 x}$.

En conjunto la cultura del Barroco - propone Maravall- responde al repertorio de recursos de persuasión con que los príncipes seiscentistas tratan de hacer propaganda de sus regímenes, con fines de integración dentro de la dominación social dada; así la comedia moderna española incluye contenidos de propaganda social. «El teatro español (escribe) trata de imponer o de mantener la presión de un sistema de poder, y por consiguiente una estratificación y jerarquía de grupos, sobre un pueblo que en virtud del amplio desarrollo de su vida durante casi dos siglos anteriores, se salía de los cuadros tradicionales del orden social, o por lo menos parecía amenazar seriamente con ello.»

En el fortalecimiento de la vigencia de la sociedad señorial se encuentra comprometido el teatro barroco, que hace recaer la moral social más meritoria en quienes ateniéndose a su estado, buscan las perfecciones propias del mismo: "Yo soy quien soy", exclaman los personajes en la fórmula que sintetiza la moral social postulada por la comedia.

El principio ordenador del grupo humano resulta por tanto el de la pertenencia estamental, y así han de entenderse en general las referen-

26 José Portolés valora en su tesis doctoral de una manera muy sombría el trabajo de don Dámaso: «En la concepción de la creación poética escribe- de Dámaso Alonso, más que sus posibles conocimientos de poesía influye su condición de poeta. Ésta favorece el alejamiento de consideraciones "científicas" en favor de argumentos de estirpe romántica que entronizan la poesía en las inalcanzables alturas de lo cuasi divinow (Medio siglo de filología española. Madrid, Cátedra, 1986. p. 172). Cierta verdad hay en esto, pero no creemos que sea toda la verdad; más bien se trata de algo visible en las declaraciones de Dámaso Alonso que operativamente asumido: en su saber literario nunca ha faltado la ciencia filológica y poética.

27 Lo villano... Madrid, Castalia, 1985; Teatro.... Madrid. Seminarios y Ediciones. 1972.

Teníamos pensado dar noticia de la obra de Salomon. pero habiendo desaparecido don José Antonio Maravall mientras estas páginas se están redactando. nos referimos a su trabajo en tanto un pequeño homenaje. Deseamos evocar -aunque ahora sea de pasada - a la persona inteligente y capaz, al caballero educado y acogedor que fuc don José Antonio; el trato y conversación con él durante los diez años últimos de su vida queda para nosotros como uno de los pequeños tesoros personales de nuestra alma. 
cias que se hacen a la sangre: "Las referencias a la "sangre" (es la idea de nuestro autor), no aluden a manchas de judaísmo de conversos, sino a la diferencia - fundamental en todo régimen social de nobleza hereditaria, como era el español y el de todos los países europeos-, entre la buena sangre del noble y la sangre vil del plebeyo" 29 .

Otra fórmula característica de los textos teatrales e ideológicamente conservadora es la de la vida como sueño: si en el mundo todos somos representantes y por tanto fingimos lo que no somos, «seamos lo que fingimos», proclama Calderón. Nos hallamos ante una fórmula también al servicio de las pretensiones inmovilizadoras de una sociedad nuevamente vigorizada en su estatismo.

En fin, Maravall contrasta también el sentido del discurso teatral con el de la novela picaresca, y dice: "La bipolar diferenciación de ricos y pobres... se da en el teatro como en la novela picaresca, sólo que en esta última para aceptar o rechazar el fenómeno, se recoge lo que en él hay de problemático, poniendo de manifiesto la dura realidad social que entraña, mientras que en el teatro... se presenta al público el espectáculo de su ordenada disposición, de su final armonía, que más de una vez se quiere hacer reconocer como inserta en el orden divino" "31.

En una conferencia complementaria de su volumen sobre el teatro, nuestro autor insistió de nuevo en cómo se trataba de suscitar adhesiones que contuviesen a las masas en la obediencia al régimen señorial, adhesiones emotivas y de raices extrarracionales: así, "la comedia va a ser el instrumento para socializar una nueva ideología, formulada adecuadamente para la población aglomerada de las ciudades». Con el entretenimiento de la fiesta, los ánimos descansaban y las malas noticias y malos pensamientos quedaban difuminados ${ }^{31}$.

\section{ESTUDIOS GONGORINOS}

En estos últimos veinte años el estudio de Góngora ha recibido aportaciones de envergadura: los grandes especialistas han seguido pu-

$2 y$ Una interpretación opcional a la de Américo Castro y sus discípulos en torno a Fernando de Rojas la planteó Maravall con lucidez en El mundo social de "La Celestina*, Madrid. Gredos, 1973.

wi Como se sabe, en torno a La literatura picaresca desde la historia social escribió nuestro áutor su última obra; una idea del contenido de la misma está en el periódico $E l$ Pais del 27 de noviembre de 1986.

"Cfr. J. A. Maravall. "Sociedad barroca y "comedia" española». F. Ruiz Ramón. coord., II Jornadas de teatro clásico español. Madrid. Ministerio de Cultura, 1980. pp. 35-60. Sobre sociedad y teatro del XVIII vid, de neustro autor - por ejemplo- «La función educadora del teatro en el siglo de la llustración". en los Estudios dedicados a Juan Peser Aleixandre. Universidad de Valencia. 1982, II, pp. 617-642. 
blicando y han reunido sus escritos, mientras otros han alcanzado el mismo relieve o trabajan con conciencia.

Los volúmenes V, VI y VII de las Obras Completas de don Dámaso se hallan dedicados por entero a «Góngora y el gongorismo» ${ }^{32}$, mientras por su lado Orozco ha publicado sucesivamente el tomo documental En torno a las "Soledades» de Góngora, el Lope y Góngora frente a frente, y la nueva Introducción a Góngora con doble número de páginas respecto de su primera salida ${ }^{33}$. Un estudioso como Vilanova no ha olvidado - entre sus otras ocupaciones- la dedicación gongorina: «Góngora y su defensa de la oscuridad como factor estético» ${ }^{34}$.

Realmente el nuevo enfoque de la biografía y de los contenidos de don Luis habría de venir con el detallado y extenso trabajo de Robert Jammes Études sur l'oeuvre poétique de don Luis de Góngora y Argote ${ }^{35}$. Obra análoga y equiparable a la de Salomon sobre Lope, va trazando al pasar de sus páginas una etopeya del autor cordobés que supone otros tantos rasgos de su poesía y teatro, a saber: andalucismo provinciano, tradicionalismo (pero no tanto ideológico como vital), anticonformismo, apoliticismo y tibieza religiosa, y sensualidad; puede verse que se trata de datos psicológicos compatibles y coherentes entre sí. A la vez - aunque contradictoriamente-, atracción cortesana llevada por circunstancias personales de don Luis, y movida también por circunstancias generales de la política del Reino.

En fin, podemos decir que la tradición de estudios gongorinos se continúa ahora con rigor en los artículos y ediciones de Antonio Carreira $^{36}$.

HACIA UN ESTUdIO DE LOS SIGLOS XVI Y XVII

Nos habíamos propuesto en las presentes páginas iniciar un comentario bibliográfico acerca de la literatura técnica en torno al Seiscientos español; por supuesto sólo hemos podido mencionar algunos autores y obras, por lo que este primer artículo resulta forzosamente muy incompleto, e incluso de varias publicaciones nada más que damos ahora el título, aunque otras están sintetizadas en lo que nos ha parecido esen-

32 Madrid, Gredos, 1978-1984.

${ }^{33}$ Emilio Orozco Díaz. En torno..., Universidad de Granada, 1969; Lope..., Madrid, Gredos, 1973; Introducción..., Barcelona, Crítica, 1984. Esta última obra está reseñada en EPOS. I.

Homenaje a José Manuel Blecua, Madrid, Gredos, 1983, pp. 657-672.

35 Université de Bordeaux, 1967.

36 Aprovechamos la presente mención para agradecer explícitamente a este companero su bondad para con nosotros ante un error por nuestra parte. 
cial. Creemos que las bibliografías analíticas deben recoger en abreviatura el contenido de aquellos trabajos que mencionan: enumerarlos nada más quizá sin haberlos visto siquiera materialmente, tomando la referencia de cualquier repertorio, del periódico, o del fichero de una biblioteca, desde el punto de vista del conocimiento no sirve casi para nada.

Para concluir las presentes páginas queríamos hacer también algunas observaciones:

a) El estudio del «Siglo de Oro» literario español debe hacerse delimitando nítidamente lo que son dos momentos diferenciados en la historia, lo que - para entendernos- Ilamaremos siglo del Renacimiento y siglo del Barroco. Las referencias globales a una época de particular esplendor deben ir quedando sustituidas en favor de una más grande rigurosidad analítica, que distinga con detalle y matización caracteres que se dan y van cambiando sucesivamente. Ya don Antonio Ballesteros decía elogiando a Karl Brandi: "Como buen historiador, Brandi es un esclavo de la cronología” ${ }^{37}$.

Si no obstante hablamos del siglo o los siglos de oro como época de apogeo literario, debemos saber a qué espacio temporal nos referimos. Muchas respuestas se han dado a esta cuestión, y a ellas vamos a añadir la que nosotros personalmente hemos concebido. Proponemos entender por «Siglo de Oro» de nuestras letras al efectivamente siglo o centuria que va de 1526 a 1635 , tomando por supuesto estas fechas a modo de símbolo, no con exactitud absoluta; 1526 es el año del encuentro de Boscán con Navagero, y 1635 el de la muerte de Lope.

Lo que tiene de fecha inicial el año 26 lo destacó ya hace tiempo don José Fernández Montesinos, quien escribia: "Nos es forzoso mirar... la complicada malla que son los acontecimientos de estos años de 1526-1536, el decenio más dramático en los destinos del Imperio y el período inicial de nuestra literatura moderna. El alumbramiento de la nueva literatura es uno de los pocos fenómenos históricos que pueden fecharse con precisión casi absoluta» ${ }^{38}$. Luego de Garcilaso vendrán Delicado, los Valdés, Guevara, Las Casas, el Lazarillo, Santa Teresa, el Brocense y Huarte, Herrera, Fray Luis, Juan de la Cueva, San Juan, López Pinciano, Cervantes, y todos los más grandes autores del Barroco.

37 «Epílogo» a K. Brandi, Carlos V, trad. cast., Madrid, Editora Nacional, 1943. p. 535.

3* J. F. Montesinos. Ensayos y estudios de literatura española, Madrid. Revista de Occidente, 1970, p. 56. 
De 1526 a 1635 proponemos - pues- entender nuestro Siglo de Oro literario 39.

b) El estudio de la época exigirá un decidido esfuerzo personal de lectura, tanto de textos como de bibliografía. Obras de envergadura y extensas como las que vienen produciendo los hispanistas franceses - por ejemplo-, no se las puede entender con sólo echarles un vistazo, o interpretándolas a través de una reseña; desde luego algo análogo se podría decir del Quijote, el Guzmán o La picara Justina.

c) El avance de la interpretación será más notorio si la preside el buen sentido estimativo. Dar noticia de autores de segunda o tercera fila importa acaso menos que intentar entender a los grandes creadores; falta por ejemplo editar parte de la prosa de Quevedo, y estudiar su pensamiento de un modo sistemático, y su lengua y estilo.

d) Idealmente la mejor garantía interpretativa en el estudio de los siglos XVI y XVII, es la de tener en cuenta de manera unitaria la literatura, la historia y la lengua, es decir, la de operar según el modo metodológico de la escuela de Menéndez Pidal. Los hechos literarios, lingüísticos e históricos son inseparables entre sí.

La literatura por supuesto es forma, forma del contenido más forma de la expresión, pero además expresa unas sustancias del contenido, las denota y connota. Toda obra tiene lugar en la serie artística, responde a un género o «institución» literaria de la que es un caso, pero además lleva en sí un significado, y acaba por denotarlo-connotarlo.

Sería un error interpretar todos los rasgos de un texto fuera de su fenomenología literaria, pues quizá tengan su sentido en ella, pero mutila también la realidad creer que lo literario acaba en lo estilístico; el mismo afán y rigor habrá de procurarse al considerar formalmente una obra e interpretar su sentido literario, que cuando intentemos hacernos cargo de su significado ideológico-cultural.

A veces los filólogos y los historiadores se estiman con recelo, y también los lingüistas y los estudiosos de la literatura, pero nada mejor al analizar un texto -idealmente-, que procurar tener a la vez la sensibilidad y los saberes técnicos de todos ellos. La incomprensión mutua entre lingüistas y estudiosos literarios se agranda en nuestros días, y nada nos parece más desgraciado para las tareas filológicas. Por supuesto para entender de verdad la historia de la literatura, la historia

\footnotetext{
36) (Con posterioridad hemos pensado que hablar del período 1556-1665 no resulta menos válido o incluso lo es más].
} 
de las ideas lingüisticas, etc., hace falta también estar versado en historia general e historia del pensamiento.

e) Finalmente queremos decir que, junto a autores de monografías, una comunidad profesional necesita de quienes elaboren obras de conjunto que se hagan cargo de los hallazgos de esas monografías. Por desgracia -no obstante-, quizá hoy se hacen más los manuales a partir de otros manuales, que no teniendo en cuenta los estudios particulares. Queda pues una notoria tarea para la que harán falta muchos esfuerzos personales más la ayuda institucional, empezando quizá por que haya bibliotecas y que funcionen bien. 